Revista Mexicana de Economía y Finanzas, Vol.11, No. 1, (2016), pp. 79-101

\title{
COMPETITIVIDAD DEL SECTOR EXTERNO MEXICANO: UN ANÁLISIS DE LA CONDICIÓN MARSHALL-LERNER Rosalinda Arriaga Navarrete*
}

Universidad Autónoma Metropolitana-Iztapalapa, Departamento de Economía Heri Oscar Landa Díaz

Universidad Autónoma Metropolitana-Iztapalapa, Departamento de Economía

(Recibido 24 de agosto 2015, aceptado 10 de diciembre 2015)

\section{Resumen}

Este artículo analiza el efecto del tipo de cambio real sobre las fluctuaciones de la balanza comercial. Para ello, se operacionaliza la hipótesis Marshall-Lerner para el caso de la economía mexicana durante el periodo 1986-2014. La estimación empírica, se efectúa con base en un modelo de vectores autorregresivos con corrección de error (VEC). Los resultados muestran que en el largo plazo el tipo de cambio real mejora la posición de la balanza comercial, asimismo, se encuentra evidencia que valida en el corto plazo el supuesto de la curva J.

\section{Abstract}

This article analyzes the effect of real exchange rate fluctuations on the trade balance. For this, the Marshall- Lerner hypothesis is operationalized in the case of the Mexican economy during the period 1986-2014. The empirical estimation is made based on a vector autoregression model with error correction ( VEC ). The results show that in the long run the real exchange rate improves the position of the trade balance also is evidence that validates the short -term course of the curve J.

Clasificación JEL: F30, F31, F32, F41

Palabras clave:: Balanza comercial, Tipo de cambio real, Condición Marshall-Lerner, Modelo Dinámico.

* San Rafael Atlixco \#186 Col. Vicentina, Iztapalapa C.P. 09340, México D.F. Tel. (55) 395959 71. Correo electrónico: luna@xanum.uam.mx 


\section{Introducción}

Con el agotamiento del modelo de industrialización sustitutiva y los desajustes macroeconómicos acumulados durante esta fase, la economía mexicana inicia la transición hacia un modelo de crecimiento hacia afuera, apuntalado en la liberalización económica y financiera.

El eje particular de este nuevo enfoque estaría dirigido a consolidar la estabilidad macroeconómica y el sector manufacturero de exportación, como núcleos de un proceso de desarrollo estable. Esta estrategia de crecimiento estaría fundamentada en los acuerdos de libre comercio, siendo la firma del Acuerdo General sobre Aranceles Aduaneros y Comercio (GATT) en 1986 el primer paso de la liberalización comercial y consolidado este proceso con la firma del Tratado de Libre Comercio de América del Norte (TLCAN) en 1994, dando paso a una nueva senda de desregulaciones, destacando la financiera por sus efectos en la balanza de pagos.

Con esta nueva fase de crecimiento, la economía mexicana ha logrado un impulso notable de las exportaciones manufactureras, modificando la composición del comercio exterior y la especialización productiva; vinculados con el fenómeno de relocalización productiva a escala internacional. En paralelo, la política cambiaria mostró transformaciones importantes, destacando la transición de un sistema fijo a uno flexible. En este sentido, el tipo de cambio real, en el primer caso, estaría determinado por el diferencial de precios foráneos y locales, mientras que en el segundo, estaría influenciado principalmente por los movimientos en el tipo de cambio nominal, debido la mayor estabilidad de los precios relativos. Con ello, la competitividad del sector exportador parece estar estrechamente asociado con el comportamiento del tipo de cambio real. Esta competitividad se refleja en la posición de la balanza comercial, la cual influye directamente en el saldo de la balanza de pagos y puede plantear restricciones al crecimiento económico.

En este contexto, nos proponemos analizar el efecto del tipo de cambio real en las fluctuaciones de la balanza comercial. Para ello, asumimos que una depreciación real de una moneda mejora, en el largo plazo, la balanza comercial y una apreciación la empeora, conforme a la hipótesis Marshall-Lerner. Esta condición establece que el volumen de exportaciones e importaciones deberá ser suficientemente elástico con respecto al tipo de cambio real; así, la suma de las elasticidades precio de la demanda de exportaciones e importaciones deberá ser mayor que uno.

El documento se organiza de la siguiente manera: En la primera sección, se presenta una caracterización del comercio exterior y de la política cambiaria en México. Con el fin de establecer las relaciones causales con el comportamiento de la balanza comercial y la competividad de la economía mexicana. En la segunda sección, se establece una revisión del estado del arte, a fin de conocer los principales resultados y metodologías empleadas en la operacionalización de la regla Marshall-Lerner. En la tercera sección, se presenta la discusión teórica y la estimación empírica de la hipótesis Marshall-Lerner para el caso de la economía mexicana. 


\section{Acuerdos comerciales, Política Cambiaria y Competitividad en México}

\subsection{Acuerdos Comerciales en México}

Desde mediados de la década de 1980, México inicia su proceso de apertura económica caracterizado fundamentalmente por la liberalización del comercio internacional y la atracción de flujos de inversión; se presenta el cambio del modelo de industrialización orientado hacia el mercado interno, el cual corresponde a la etapa sustitutiva de importaciones adoptada desde 1940, por una estrategia de industrialización orientada hacia el mercado externo. Así, México suscribe durante los años noventa la gran mayoría de los tratados de libre comercio vigentes; además de participar y competir en un entorno de gran transformación del comercio internacional, iniciado desde el año 2000 con el ingreso de China al sistema multilateral de comercio, la presencia cada vez mayor del comercio de insumos y bienes intermedios, en lugar de bienes finales y la conformación de las cadenas globales de valor.

Esta orientación del crecimiento económico basada en el dinamismo de los mercados externos tiene como pilar la apertura comercial, en el marco de los acuerdos comerciales y la desregulación financiera que facilitaría el acceso a los mercados internacionales de capital, con una menor participación del Estado como promotor del desarrollo.

Desde su adhesión en 1986 al Acuerdo General sobre Aranceles Aduaneros y Comercio (GATT), México ha tenido un gran avance en su apertura al comercio y la inversión internacionales y ha cosechado los beneficios derivados de esta decisión. La liberalización unilateral aunada a varios convenios bilaterales, multilaterales y regionales, incluido el Tratado de Libre Comercio de América del Norte (TLCAN) en 1994, crearon un ambiente propicio para el comercio y la inversión. Según los datos del Banco Mundial: las exportaciones de bienes y servicios se multiplicaron hasta por 14 veces entre 1985 y 2013, al pasar de 28,436 millones de pesos a 400,326 millones de pesos.

En relación a los flujos de IED hacia México, en 1985 esta representó $0.9 \%$ del PIB (1,729 millones de dólares), para 1995, con la entrada en vigor del Tratado de Libre Comercio alcanzó la cifra de $2.4 \%$ del PIB (8,374 millones de dólares), mientras que en 2013 esta participación alcanzó 2.8 puntos porcentuales del PIB (35,188 millones de dólares). Este mayor flujo de IED responde en buena medida al proceso de desregulación financiera que, entre otros efectos, permitio la apertura de la cuenta de capital, lo que se tradujo en una mayor inversión directa y de cartera por parte de inversionistas extranjeros. Según se observa en el en el cuadro 1, el sector industrial destaca como el principal polo de atracción de los flujos de IED, al pasar de 1,183 millones de dólares en 1985 a 29,920 millones de dólares en 2013, alcanzando una participación promedio del $58.4 \%$ del total de la inversión. Asimismo, el proceso de liberalización financiera promovio un aumento de la IED en el sector servicios, particularmente en servicios financieros, pasando de 544 millones de dólares en 1985 a alrededor de 5,200 millones de dólares en 2013. Cabe destacar que el nivel más alto de IED como proporción del PIB (4.1\%) se alcanza en 2001, como efecto de la compra de activos en el sector de servicios financieros. 
Cuadro 1. México: Flujo de Inversión Extranjera Directa (Millones de dólares)

\begin{tabular}{|l|r|r|r|r|r|r|r|}
\hline \multicolumn{1}{|c|}{ Periodo } & \multicolumn{1}{c|}{1985} & \multicolumn{1}{c|}{1990} & \multicolumn{1}{c|}{1995} & \multicolumn{1}{c|}{2000} & \multicolumn{1}{c|}{2005} & \multicolumn{1}{c|}{2010} & \multicolumn{1}{c|}{2013} \\
\hline Total & $1,729.0$ & $3,722.4$ & $8,374.6$ & $18,298.0$ & $24,668.9$ & $23,027.4$ & $35,188.4$ \\
\hline Agropecuario & 0.4 & 61.1 & 10.0 & 97.5 & 15.7 & 91.5 & 75.5 \\
\hline Industrial & $1,183.8$ & $1,286.8$ & $4,493.3$ & $10,774.3$ & $11,753.2$ & $14,004.8$ & $29,920.1$ \\
\hline Servicios & 544.8 & $2,374.5$ & $3,871.4$ & $7,426.3$ & $12,899.9$ & $8,931.0$ & $5,192.7$ \\
\hline
\end{tabular}

Fuente: Elaboración propia con datos de Secretaria de Economía y Banxico

En este contexto, Pacheco (2005) destaca que un aspecto central de la apertura económica fue la atracción de flujos de inversión extranjera directa (IED) para estimular el crecimiento económico y asegurar el acceso al mercado de Estados Unidos. Se presupuso que por medio de los altos flujos de IED se reforzaría la capacidad de exportación y se generaría un boom exportador; además, se consideró que el TLCAN era una señal para otros inversionistas extranjeros que podrían ubicarse en México y acceder al mercado estadounidense.

En la misma línea de argumentación, Estrada y Arriaga (2004) señalan que con la entrada de México al GATT y la firma del TLCAN se observan un conjunto de cambios fundamentales en la estructura y forma de operar de la economía mexicana; entre los cuales destacan el impulso a la relocalización de empresas extranjeras hacia el espacio nacional y, como consecuencia, el crecimiento del comercio exterior, con un alta concentración hacia el mercado de Estados Unidos. Otro modificación sustantiva subyace en la eliminación de los permisos de importación y la desgravación arancelaria. La cobertura de las restricciones cuantitativas, ${ }^{1}$ basadas en el arancel promedio ponderado paso de $27 \%$ en 1982 a $11.8 \%$ en 1995, ya con la entrada en vigor del Tratado de Libre Comercio (TLCAN), hasta promediar 7.9\% en 2013.

Como se observa en la Gráfica 1, Entre 1970 y 1985 el comercio internacional de México representaba alrededor de 19.3 puntos porcentuales del PIB; con la entrada de México al GATT en 1986 y hasta la entrada en vigor del TLCAN, la importancia del volumen comercial ascendió a $29.3 \%$ del PIB. Ya con la consolidación del principal tratado comercial de México 1995-2014, el volumen comercial representa alrededor de 55 puntos porcentuales del PIB, donde la participación de las exportaciones e importaciones es similar $(27.2 \%$ y $27.8 \%$ respectivamente).

\footnotetext{
1 Datos basados en las estadísticas de los perfiles arancelarios en el mundo de la OMC y Sánchez (2012). Para 1995 y 2014 el arancel promedio ponderado se refiere al NMF aplicados (Nación más favorecida).
} 
Gráfica 1. México Grado de Apertura Comercial

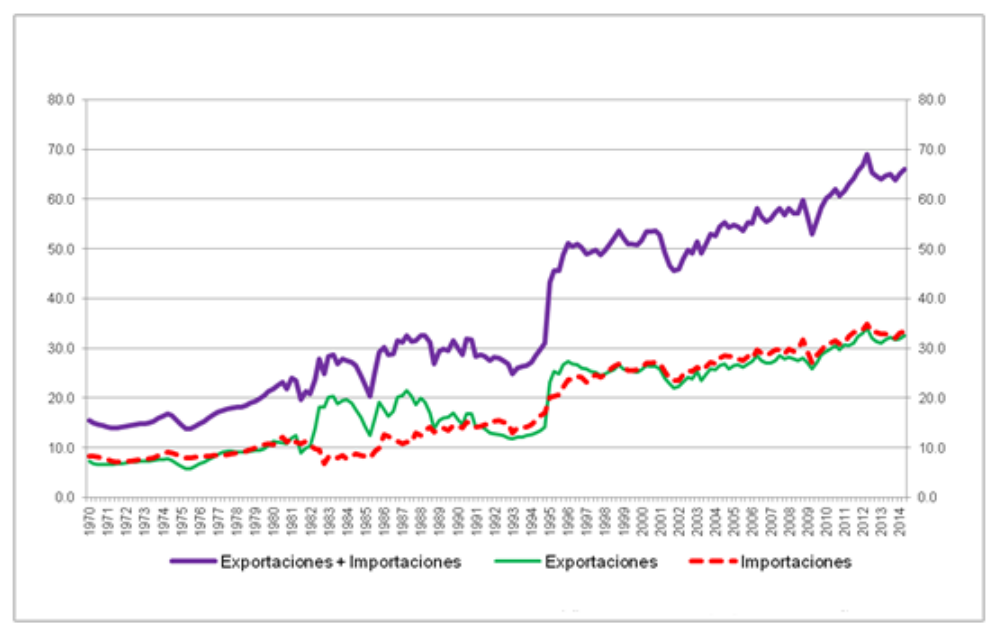

Fuente: Elaboración propia con información de la OCDE

Efectivamente, las reformas al régimen de comercio exterior tuvieron entre otros efectos, el aumento exponencial de las exportaciones. Con base en cifras de la OCDE, entre 1985 y 2014, las exportaciones crecieron a una tasa anual promedio de $6.2 \%$; sin embargo, luego de la firma del TLC y el año anterior a la crisis del 2008 el crecimiento de las exportaciones fue superior, alcanzando una tasa del $7.3 \%$ promedio anual. Este notable crecimiento exportador se encuentra asociado con la rápida expansión del sector manufacturero, cuyas exportaciones durante el periodo 1994-2014 crecieron a una tasa promedio anual del $10 \%$, siendo superior al flujo total de exportaciones.

El éxito exportador de la economía mexicana promovió 2 fenómenos: la transformación de la estructura del comercio exterior y la concentración geográfica de las exportaciones. El primero, asociado con rápido crecimiento de las exportaciones no-petroleras, en contraste a la baja sensible de las exportaciones petroleras, así como fuerte expansión de las exportaciones manufactureras y maquiladoras. Entre 1980 y 2014, la participación de las exportaciones no petroleras en el flujo total de exportaciones pasó de $42.1 \%$ a alrededor de $89.3 \%$. En tanto que el peso relativo de las exportaciones manufactureras en el flujo total, paso $30.8 \%$ en 1980 a una participación del $84.9 \%$ en el valor total de las exportaciones. Por otro lado, a inicios de los 80s las exportaciones maquiladoras constituían apenas $14 \%$ del flujo total, para 2006 esta cifra ascendía ya a $44.7 \%$ (Landa, 2010).

En el segundo caso, lo constituye la concentración de las exportaciones (destino), así como la incipiente diversificación de importaciones (origen). Como se observa en el Cuadro 1, en 1985, 62.3\% de las exportaciones totales tuvieron como destino el mercado estadounidense, incrementando esta participación al $80.2 \%$ en 2014. Conviene destacar que hasta el año 2000, la dinámica de las ventas del sector exportador hacia Estados Unidos alcanzan su máxima participación y muestran un punto de inflexión en dicha participación; coincidente con la entrada de la economía China a la OMC. En este sentido, destaca 
Acevedo (2012) que en los primeros años del TLCAN, la competencia mexicana en el mercado estadounidense estaba concentrada en países con salarios relativamente más elevados que los mexicanos, como Canadá, Inglaterra, Japón, Alemania y Suecia. Sin embargo, con la incorporación de China ${ }^{2}$ a la economía mundial y su adhesión a la OMC, modifica la situación ventajosa de México.

Por otra parte, se observa en el cuadro 2 que las importaciones de México no presentan esa alta concentración hacia el mercado norteamericano, aun cuando las importaciones provienen en primera instancia de Estados Unidos. Si bien, para 1985 el $67.6 \%$ de las importaciones mexicanas provenían del mercado de Estados Unidos y sólo 5.4\% del mercado asiático, para el 2014 esta composición ha cambiado notablemente, donde las ventas de Estados Unidos hacia México representan en el $49 \%$ de las importaciones totales, destacando la participación relativa del mercado asiático con cerca del $24 \%$, porcentaje en el cual la contribución de China es $16.6 \%$. Al respecto Acevedo (2012) sostiene que la menor concentración de las importaciones se debe, entre otras cosas, a que muchas de las exportaciones que realiza México a los EUA utilizan insumos provenientes de Asia y a la mayor diversificación del consumo final.

Cuadro 2. Exportaciones principales socios comerciales (Participación \%)

\begin{tabular}{|l|r|r|r|r|r|r|r|r|r|r|}
\hline Periodo & 1970 & 1975 & 1980 & 1985 & 1990 & 1995 & 2000 & 2005 & 2010 & 2014 \\
\hline Totales & 100.0 & 100.0 & 100.0 & 100.0 & 100.0 & 100.0 & 100.0 & 100.0 & 100.0 & 100.0 \\
\hline Estados Unidos & 71.0 & 60.5 & 64.6 & 62.3 & 70.0 & 83.3 & 88.7 & 85.7 & 80.0 & 80.2 \\
\hline Canadá & 1.0 & 1.5 & 0.8 & 1.7 & 0.8 & 2.5 & 2.0 & 2.0 & 3.6 & 2.7 \\
\hline China & - & 1.2 & 0.6 & 0.4 & 0.0 & 0.0 & 0.1 & 0.5 & 1.4 & 1.5 \\
\hline España & 1.2 & 0.7 & 8.0 & 7.8 & 5.5 & 1.0 & 0.9 & 1.4 & 1.3 & 1.5 \\
\hline Brasil & 1.2 & 3.2 & 2.6 & 1.4 & 0.6 & 1.0 & 0.3 & 0.4 & 1.3 & 1.2 \\
\hline $\begin{array}{l}\text { Part \% de México en } \\
\text { el flujo mundial }\end{array}$ & 0.4 & 0.3 & 0.9 & 1.4 & 1.2 & 1.5 & 2.6 & 2.0 & 1.9 & 2.1 \\
\hline
\end{tabular}

Fuente: Elaboración propia con datos de Secretaria de Economía, BADECEL y OMC

\footnotetext{
2 La adhesión de China a la OMC en 2001, presentó grandes cambios en la economía global, particularmente aparece como un gran competidor en el mercado estadounidense y resta el posicionamiento de México en las importaciones norteamericanas, afectando su competitividad. De esta manera señala Acevedo (2012) que en el primer año de su pertenencia a la OMC, China expandió sus exportaciones globales y las destinadas a Estados Unidos 22 y $29 \%$, respectivamente.
} 
Cuadro 2.Importaciones principales socios comerciales (Participación \%)

\begin{tabular}{|l|r|r|r|r|r|r|r|r|r|r|}
\hline Periodo & \multicolumn{1}{|c|}{1970} & \multicolumn{1}{|c|}{1975} & \multicolumn{1}{|c|}{1980} & \multicolumn{1}{|c|}{1985} & 1990 & 1995 & 2000 & 2005 & 2010 & 2014 \\
\hline Totales & 100.0 & 100.0 & 100.0 & 100.0 & 100.0 & 100.0 & 100.0 & 100.0 & 100.0 & 100.0 \\
\hline Estados Unidos & 63.6 & 62.8 & 68.0 & 67.5 & 67.1 & 74.4 & 73.1 & 53.4 & 48.1 & 48.8 \\
\hline China & 0.0 & 0.1 & 0.3 & 0.3 & 0.1 & 0.7 & 1.7 & 8.0 & 15.1 & 16.6 \\
\hline Japón & 3.5 & 4.7 & 5.0 & 5.0 & 4.3 & 5.5 & 3.7 & 5.9 & 5.0 & 4.4 \\
\hline Corea del Sur & 0.0 & 0.0 & 0.1 & 0.1 & 0.6 & 1.3 & 2.2 & 3.0 & 4.2 & 3.4 \\
\hline Alemania & 7.5 & 7.3 & 5.4 & 4.3 & 5.6 & 3.7 & 3.3 & 3.9 & 3.7 & 3.4 \\
\hline $\begin{array}{l}\text { Part. \% de México en } \\
\text { el flujo mundial }\end{array}$ & 0.7 & 0.7 & 1.1 & 0.9 & 1.2 & 1.4 & 2.7 & 2.1 & 2.0 & 2.2 \\
\hline
\end{tabular}

Fuente: Elaboración propia con datos de Secretaria de Economía, BADECEL y OMC

En resumen, el comercio exterior de la economía mexicana se caracterizo por un dinamismo exportador, basado en un alto contenido de insumos importados; atribuido a los profundos cambios en la economía global que muestran una forma de producción a escala internacional y de fragmentación de los procesos productivos. En este sentido, Romero (2009) señala que la alta concentración de las exportaciones mexicanas en el mercado estadounidense se explica en buena medida porque las exportaciones son realizadas por empresas estadounidenses, a través del comercio intra-firma de procesos productivos fragmentados, así este tipo de comercio se explica por dotación de factores y la liberación comercial para el país en desarrollo implica una amplia reasignación de factores entre industrias.

Conviene señalar que en el análisis de los flujos comerciales de un país, el valor agregado exportado es fundamental, toda vez que el comercio global se caracteriza por las cadenas de valor a escala internacional. El valor agregado exportado puede ser definido como las exportaciones menos las importaciones necesarias para producirlas. En un amplio trabajo acerca de las estimaciones del valor agregado exportado en México, De la Cruz et al (2011) indican que el valor agregado exportado promedio de las exportaciones manufactureras de México es del $34 \%$ aproximadamente. Las industrias que tienen un contenido nacional inferior al 50 por ciento representan aproximadamente el 80 por ciento de las exportaciones manufactureras del país. Aunque es relativamente bajo, el valor agregado nacional de las exportaciones de México se ha incrementado en los últimos años lo que sugiere, señalan los autores, que la estrategia industrial de México ha dado como resultado, aunque modestamente y en algunas industrias solamente, su inserción en las cadenas productivas globales.

\subsection{La competitividad de las exportaciones mexicanas y la política cambiaria}

En la literatura económica se reconoce que un factor determinante del mayor volumen comercial y de la competitividad del sector exportador está asociado con la evolución del tipo de cambio real. ${ }^{3}$ En un sistema de tipos de cambio fijo, el diferencial de precios (términos de intercambio) indica el diferencial entre el

\footnotetext{
3 Las exportaciones mexicanas fueron promovidas por un tipo de cambio real alto, resultado de la depreciación del peso de 1995; el acceso preferencial al mercado norteamericano provisto por el TLCAN; y el gran dinamismo de la economía de Estados Unidos (1997-2001).
} 
tipo de cambio nominal y tipo de cambio real. Si el diferencial de precios de ambas economías es estable no hay diferencia entre los tipos de cambio. En contraste, en un sistema de tipos de cambio flexible, la volatilidad del tipo de cambio nominal y el diferencial de precios puede acentuar las diferencias entre los tipos de cambio.

A nivel internacional, la implementación del sistema de tipos de cambio fijo emerge con los Acuerdos de Bretton Woods, enfocados a la estabilidad de los tipos de cambio, basado en el control de los movimientos de capital. Con la caída del sistema de Bretton Woods en 1973, los países industrializados sustituyeron el régimen de tipo de cambio fijo por el flotante y es hasta la década de los ochenta y noventa que la mayoría de los países en desarrollo lo modificaron.

Durante el periodo de tipo de cambio fijo en México, 1954 a 1976, el diferencial de precios entre la economía nacional y la norteamericana fue muy acentuada, el crecimiento de los precios para el caso de México durante este período fue del $313 \%$, mientras que para Estados Unidos fue del $112 \%$, acumulando sobrevaloraciones y desequilibrios en la balanza de pagos por la pérdida de competitividad. Es importante anotar que entre 1976 y 1982, se estableció un sistema de flotación controlada, derivado de la inestabilidad de los precios internacionales del petróleo. Posteriormente, con la depreciación cambiario de 1982 y la creciente inflación se acentúo la brecha de los precios entre ambas economías, como destaca Gómez y Rodríguez (2011), entre 1985 y 1991 la economía mexicana experimentó un crecimiento de los precios de $1,623.8 \%$, mientras que en Estados Unidos fue de sólo $26.57 \%$. En este contexto inflacionario, ${ }^{4}$ una medida inmediata de política monetaria, implementada en el periodo 1991-1994, fue la efectividad de los programas de control inflacionario y la consecuente reducción del diferencial de precios en ambas economías, $35.6 \%$ para México y $8.83 \%$ para Estados Unidos.

A pesar del control de la inflación logrado hasta 1994, ante la creciente inestabilidad de los mercados financieros y el ataque especulativo a las reservas internacionales del Banco de México indujeron a las autoridades a adoptar un régimen de libre flotación del tipo de cambio. De esta manera, desde diciembre de 1994 a la fecha, el tipo de cambio se determina por la oferta y la demanda de divisas. Así, las variaciones del tipo de cambio real y el correspondiente efecto sobre la competitividad dependerán del tipo de cambio nominal, ya que el Banco Central establece como ancla nominal de la política monetaria el control inflacionario. A partir del periodo de tipos de cambio flexible, se ha reducido sensiblemente la brecha en el diferencial de precios, en 1994 la inflación en México fue del $7.1 \%$, mientras que en Estados Unidos fue del $2.7 \%$, ya para $2014^{5}$ la economía mexicana tuvo una inflación de $4.3 \%$ y Estados Unidos del

Así, las exportaciones mexicanas a ese país crecieron $246 \%$ y pasaron de representar $6.7 \%$ de las compras externas estadounidenses en 1993, a $11.8 \%$ ocho años después. (Revisar cuadros de importaciones, pues son idénticos, exportaciones e importaciones).

4 En el periodo 1987-1994, las autoridades utilizaban la política de tipo de cambio como ancla nominal de los precios, para controlar la inflación implementaron un pacto entre los sectores privado, público y social para establecer el aumento en los salarios mínimos, la tasa de depreciación y el precio de los energéticos. (Gómez y Rodríguez (2011).

5 Información anualizada con respecto al mismo mes del año anterior. Para el año 2014 
$1.7 \%$.

Con la implementación de la política comercial y la liberalización financiera, se establece como elemento central la reducción de los desequilibrios externos, mediante la complementariedad entre la cuenta corriente y la cuenta de capital. Con lo cual, los movimientos del tipo de cambio real se corresponden con la oferta y demanda de los flujos de divisas. Conviene recordar, que la apertura de la cuenta de capital al mercado valores, incrementa de manera importante los flujos de divisas, mediante la adquisición de activos productivos y financieros ó mediante los prestamos e instrumentos de deuda.

Gráfico 2. México Competitividad y Balanza de Pagos

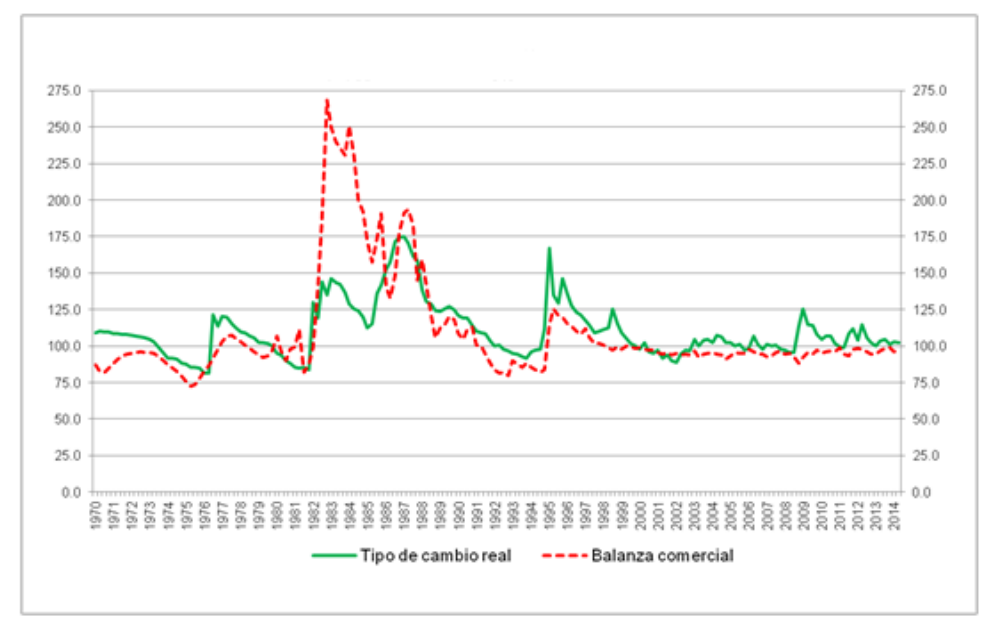

Fuente: Elaboración propia con información de la OCDE

Según se observa en la gráfica 2, la mayor competitividad del comercio exterior mantiene un movimiento sincronizado con la evolución del tipo de cambio real. ${ }^{6} \mathrm{Si}$ bien, durante los periodos de crisis económica, 1982-1994, que se corresponden con tipos de cambio fijo, es más evidente la mejor posición de la cuenta comercial, esta se asociada a las depreciaciones cambiarias, lo que mejora la competitividad. Destaca que luego de la implementación del tipo de cambio nominal flexible, el comportamiento del tipo de cambio real en el largo plazo es muy estable, condición que se atribuye a la estabilidad de precios; a diferencia de la fase de tipo de cambio nominal fijo, donde el tipo de cambio real absorbe el enorme diferencial de precios entre México y Estados Unidos, traduciéndose en pérdidas de competitividad.

se considera la variación de precios entre octubre del 2013 y octubre del 2014.

6 Un aumento del tipo de cambio real supone una depreciación de este, mejorando de esta manera la competitividad de las exportaciones de un país. En caso contrario, una disminución del índice del tipo de cambio real presupone una apreciación de este, conllevando a una pérdida de competitividad. Para este trabajo partimos de la definición del tipo de cambio nominal a partir de la paridad dólar-peso mexicano. Conviene recordar que el tipo de cambio real = tipo de cambio nominal ponderado por la relación de precios foráneo y doméstico. 
En suma, en México, durante el periodo de tipos de cambio fijo, la enorme brecha en el diferencial de precios entre Estados Unidos y México tuvo el mayor impacto en la pérdida de competitividad; con la implementación del tipo de cambio flexible la brecha en el diferencial de precios se redujo sensiblemente y la estabilidad del tipo de cambio real está más en sincronía con el tipo de cambio flexible, el cual depende de los flujos de entrada y salida de divisas al país.

Las profundas transformaciones del comercio mundial, basadas en políticas comerciales y de tipo de cambio flexible, constituyen un elemento fundamental en el análisis, primero, de la evolución de la balanza comercial y sus determinantes, siguiendo el enfoque Marshall-Lerner, y, segundo, de las posibles restricciones al crecimiento económico en el largo plazo vinculadas al equilibrio de la balanza comercial; aunque este último punto quedará para futuras investigaciones. Los determinantes de la balanza comercial han sido un tema ampliamente discutido por la teoría económica y en la literatura empírica, en donde se destaca la importancia del tipo de cambio real, el ingreso nacional y foráneo.

\section{Breve revisión de la literatura}

En este apartado presentamos una revisión de la literatura empírica enfocada al contraste de la condición Marshall-Lerner. En general, los resultados son mixtos, particularmente cuando se toman en cuenta las diferencias estructurales de los distintos países, lo cual conduce a diversas interpretaciones y conclusiones. La hipótesis establece, ceteris paribus, que la depreciación del tipo del cambio real mejora la balanza comercial siempre que el volumen de las exportaciones e importaciones sean suficientemente elásticos con respecto al tipo de cambio real.

En un trabajo para España, para el periodo 1965-2003, Sastre (2010) prueba la condición Marshall-Lerner mediante una extensión del modelo original. En esta propuesta el autor incluye la elasticidad cruzada entre exportaciones-importaciones como variable de ajuste del sistema original, debido a que, el dinamismo exportador conlleva a un robusto crecimiento de las importaciones, lo que Krugman (1995) llama "slicing up the product process; un efecto inmediato de lo anterior es el crecimiento del comercio a escala mundial".

En virtud de lo anterior, Sastre (2010) apunta que es fundamental para el análisis de la regla Marshall-Lerner, en el contexto de economía abierta, identificar el grado de correlación entre exportaciones e importaciones (elasticidad cruzada). Con este fin, propone un sistema biecuacional para las variables de comercio exterior, estimadas mediante un modelo dinámico. Según sus estimaciones, encuentra que las exportaciones muestran una elevada elasticidad con el indicador de competitividad (tipo de cambio) en el largo plazo y se reduce significativamente en el corto plazo. Por otro parte, halla que las importaciones son insensibles en el corto plazo, pero sensibles en el largo plazo al indicador de competitividad.

Con datos trimestrales para el periodo 1991-2008, Bustamante y Morales (2009) prueban la hipótesis Marshall-Lerner para el caso de Perú. Mediante un sistema dinámico de la regla básica de Marshall-Lerner, estiman el efecto 
del tipo de cambio real, las importaciones mundiales y el PIB doméstico sobre la balanza comercial en el largo plazo; para ello, emplean un modelo de vectores autorregresivos con corrección de error (VEC). La relevancia del estudio, afirman los autores, se debe al marcado dinamismo del comercio internacional del Perú, sustentado en importantes superávits comerciales y una nítida diversificación de los mercados de destino en la última década.

Según sus resultados, en el largo plazo, el tipo de cambio real mantiene una asociación positiva y estadísticamente significativa con la balanza comercial, mientras que la demanda mundial presenta una relación negativa, con ello verifican empíricamente la hipótesis Marshall-Lerner. Basado en funciones de impulso respuesta, encuentran que el fenómeno de la Curva-J no se cumple para el caso de estudio, pues si bien el tipo de cambio real ejerce un impacto positivo en el tiempo, este se estabiliza casi de inmediato. Los autores argumentan que una posible explicación de la notable sensibilidad de la balanza comercial al tipo de cambio se debe a la composición de la estructura productiva del comercio exterior peruano, la cual se caracteriza por el bajo valor agregado de los productos exportados (Bustamante y Morales, 2009).

Rendón y Ramírez (2005) analizan el efecto de largo plazo, para el caso colombiano, del tipo de cambio real sobre la balanza comercial durante el periodo 1980-2001, con datos trimestrales. Con este fin, emplean un modelo de Vectores Autorregresivos con Corrección de Error (VEC); el cual incluye balanza comercial, tipo de cambio real, PIB y el índice de producción de Estados Unidos. En sus resultados encuentran que la elasticidad de la balanza comercial con respecto al tipo de cambio real es mayor que uno, lo cual significa que la condición Marshall-Lerner se mantiene para la economía colombiana en el largo plazo. Asimismo, identifican que un aumento del ingreso foráneo mejora la posición de la balanza comercial, mientras que un aumento del ingreso del doméstico la reduce.

Los resultados de Hernández, et al. (2012) verifican la condición MarshallLerner para el caso de Bolivia. En su trabajo los autores especifican un sistema de Vectores Autorregresivos con Corrección de Error (VEC), estimado con datos trimestrales para el periodo 1992-2011. Según sus estimaciones el coeficiente asociado al tipo de cambio real es positivo y estadísticamente significativo, lo cual valida, argumentan los autores, el teorema Marshall-Lerner; aunque en el corto plazo no hallan evidencia de una curva J. Por otro lado, la elasticidad-ingreso domestico y foráneo muestran el signo esperado, siendo la primera superior a la segunda, en términos absolutos; aunque la diferencia es compacta, lo que podría implicar una restricción al crecimiento económico sostienen los autores.

Con el objetivo de identificar los factores determinantes de la balanza comercial en México, Galindo y Guerrero (1997), con series trimestrales para el periodo 1980-1995, plantean un modelo de vectores autorregresivos con corrección de error (VEC). El sistema de ecuaciones construido, se fundamenta en los indicadores de balanza comercial, PIB nominal de Estados Unidos, PIB de México y tipo de cambio real. Estos autores encuentran una relación estable de largo plazo entre la balanza comercial, el ingreso nacional, el ingreso de Estados Unidos y el tipo de cambio real. Concretamente, sus resultados sugieren que el PIB de México mantiene una relación negativa con la balanza comer- 
cial, mientras que el PIB de Estados Unidos y el tipo de cambio real ejercen un efecto positivo. Evidencia que sustentaría el cumplimiento de la condición Marshall-Lemer.

En su trabajo Kalyoncu et al (2009) examinan el efecto de corto y largo plazo de una devaluación sobre la balanza comercial. A tal efecto, emplean un modelo de Vectores Autorregresivos con Corrección de Error, cuya muestra recoge datos trimestrales, durante el periodo de 1979-2005, para Argentina, Brasil, México y Perú. ${ }^{7}$ Los autores encuentran una relación positiva entre tipo de cambio real y la balanza comercial, mientras que el corto plazo la asociación es negativa en los casos de Argentina y Perú; en tanto que las estimaciones para México y Brasil no muestran evidencia de cointegración. Asimismo comprueban una relación negativa (positiva) entre el ingreso doméstico (ingreso foráneo) y la balanza comercial. Con estos resultados, los autores concluyen que una depreciación del tipo de cambio real mejora la balanza comercial en el largo plazo y la empeora en el corto plazo, comprobándose para Argentina y Perú la operacionalidad de la regla Marshall-Lerner.

La literatura empírica revisada utiliza como base metodológica el contraste de Marshall-Lerner. Como se ha discutido, los resultados en general confirman el cumplimiento de la condición en el largo plazo y con menor evidencia para el corto plazo. En el presente artículo, pretendemos verificar el efecto puntual del tipo de cambio real sobre la balanza comercial, en otras palabras, los efectos que sobre la balanza comercial ejercen la apreciación o depreciación de la moneda y/o los términos de intercambio, particularmente, con el inicio de los acuerdos de libre comercio, coincidente con la entrada de México al GATT en 1986.

\section{La Condición Marshall-Lerner: consideraciones teóricas y estimación econométrica para México}

En esta sección se analiza empíricamente el planteamiento teórico de la Condición Marshall-Lerner, que establece el efecto de largo plazo del tipo de cambio real sobre la balanza comercial. Con este fin, operacionalizamos el teorema para el caso de México durante el periodo 1986-2014.

\subsection{La Condición Marshall-Lerner: una especificación para México}

El teorema Marshall-Lerner establece que si la balanza comercial se encuentra inicialmente en equilibrio, la depreciación real de una moneda mejora, en el largo plazo, la cuenta comercial y una apreciación la empeora. Esta hipótesis depende de que el volumen de exportaciones e importaciones sea suficientemente elástico con respecto al tipo de cambio real; esto implica que la suma de las elasticidades precio de la demanda de exportaciones e importaciones sea mayor que uno (Krugman y Obsfeld, 2006).

En virtud de lo anterior, podemos definir la balanza comercial como:

$$
B C=P_{X} X(e)-e P_{M} M(e)
$$

Donde $B C$ representa la balanza comercial; $X$ y $M$ constituyen las exportaciones e importaciones de bienes y servicios, mientras que $P_{X}$ y $P_{M}$ los

\footnotetext{
7 El tamaño de la muestra difiere entre los países: Argentina 1981q1-2005q4, Brasil 1993q1-2005q4, México 1979q1-2005q4 y Perú 1979q1-2005q4.
} 
precios de exportaciones e importaciones, respectivamente; siendo e el tipo de cambio real.

Para medir el afecto de una variación del tipo de cambio sobre la balanza comercial, calculamos $\partial B C / \partial e$ :

$$
\frac{\partial B C}{\partial e}=P_{X} \frac{\partial X(e)}{\partial e}-\left(P_{M} M(e)+e P_{M} \frac{\partial M(e)}{\partial e}\right)
$$

Reagrupando términos obtenemos:

$$
\frac{\partial B C}{\partial e}=P_{M} M\left(\frac{P_{X} X(e)}{e P_{M} M(e)} \frac{\partial X(e)}{\partial e} \frac{e}{X(e)}-1-\frac{\partial M(e)}{\partial e} \frac{e}{M(e)}\right)
$$

En términos de elasticidades la ecuación (3) puede expresarse como:

$$
\frac{\partial B C}{\partial e}=P_{M} M\left(\frac{P_{X} X(e)}{e P_{M} M(e)} \eta_{X}-1+\eta_{M}\right)=0
$$

Retomando el hecho de que la balanza comercial se encuentra inicialmente en equilibrio, $P_{X} X(e)=e P_{M} M(e)$, entonces:

$$
\frac{P_{X} X(e)}{e P_{M} M(e)} \eta_{X}-1+\eta_{M}=0
$$

Por lo tanto:

$$
\eta_{X}+\eta_{M}>1
$$

\subsection{Especificación econométrica}

La ecuación estimable de la condición Marshall-Lerner viene dada por:

$$
B C_{t}=\beta_{0}+\beta_{1} Y_{t}^{d}+\beta_{2} Y_{t}^{f}+\beta_{3} e_{t}
$$

Donde $Y_{t}^{d}$ e $Y_{t}^{f}$ representa el ingreso domestico y el ingreso mundial, mientras que $e_{t}$ captura el tipo de cambio real. ${ }^{8}$

Para efectos empíricos asumimos un modelo de Vectores Autorregresivos (VAR), metodología que permite capturar la relación de corto plazo de un sistema, donde las variables son consideradas endógenas. Así la ecuación (7) queda expresada de la forma

$$
X_{t}=\sum_{i=1}^{p-1} \mathrm{~A}_{i} X_{t-i}+{ }_{t}
$$

\footnotetext{
8 La definición de tipo de cambio real, aplicada a la serie temporal, es la relación de bienes extranjeros expresados en bienes nacionales; la cual es equivalente a la definición tipo de cambio nominal, moneda extranjera expresada en moneda nacional. De esta manera una subida del tipo de cambio real implica una depreciación de los bienes nacionales, favoreciendo la competitividad.
} 
Donde $X$ es un vector columna de $k$ variables endógenas (Balanza Comercial, $B C_{t}$, Producto Interno Bruto de México, PIB $B_{t}^{M e x}$, Producto Interno Bruto de Estados Unidos, PIB $B_{t}^{U S A}$, tipo de cambio real, $\left.e_{t}\right) ; A_{i}$ una matriz de coeficientes y $\epsilon_{t}$ un vector columna de perturbaciones aleatorias.

Si todas las variables son integradas del mismo orden $I(d)$ y existe una relación de cointegración entre ellas, el término de error sigue un proceso $I(0)$. Entonces, la relación de largo plazo deberá incorporar una ecuación de corrección de error, cuyo objetivo será introducir la dinámica de corto plazo de las variables, influenciadas por las desviaciones respecto de la senda de equilibrio, al comportamiento de largo plazo.

En consecuencia, es necesario rescribir el modelo VAR no restringido, ecuación (8), como un modelo vectorial de corrección de errores (VEC), como sigue:

$$
\Delta X_{t}=v+\Pi X_{t-1}+\sum_{i=1}^{p-1} \Gamma_{i} \Delta X_{t-i}+\epsilon_{t}
$$

Donde $\Delta$ es el operador de primera diferencia; $X$ un vector de $k$ variables endógenas (Balanza Comercial, $B C_{t}$, Producto Interno Bruto de México, $P I B_{t}^{M e x}$, Producto Interno Bruto de Estados Unidos, PIB $B_{t}^{U S A}$, tipo de cambio real, $e_{t}$ ), integradas de orden $I(1) ; \Pi$ y $\Gamma_{i}$ contienen, respectivamente, los parámetros de largo y corto plazo $;^{9} \nu$ es un vector de $k \times 1$ parámetros independientes; $\epsilon_{t}$ es un vector $k x 1$ de términos de errores independientes e idénticamente distribuidos.

De la especificación estocástica muestral, se espera que el coeficiente de largo plazo asociado al tipo de cambio real sea mayor que 1 y estadísticamente significativo, $\beta_{3}>1$, lo cual indicaría que la balanza comercial mejora ante una depreciación.

\subsection{Resultados econométricos}

Los datos para la estimación empírica comprenden series trimestrales para el periodo 1986:q1 al 2014:q2 de la economía mexicana. Empleamos como variable proxy de la balanza comercial el logaritmo natural de la relación exportaciones/importaciones; el ingreso doméstico y el ingreso mundial son aproximados a través del PIB de México y el PIB de Estados Unidos, respectivamente; mientras que para el tipo de cambio real se utiliza el índice de tipo de cambio real de México (paridad peso-dólar). El proceso metodológico inicia con el análisis del orden de integración de las series incluidas en nuestro modelo, mediante las pruebas de raíz unitaria de Dickey-Fuller Aumentada y Phillips-Perron. El contraste sugiere, con un nivel de significancia del $5 \%$, que las variables son integradas $I(1)$ en niveles y procesos estocásticos estacionarios $I(0)$ en primeras diferencias.

Una vez determinado el orden de integración de las series, con el propósito de determinar si existen relaciones de equilibrio (cointegración) de largo plazo

\footnotetext{
${ }^{9}$ Se asume que $\Pi$ es de rango reducido $r<k$, por lo que puede expresarse como $\Pi=$ $\alpha \beta^{T}$ donde $\alpha$ y $\beta$ son matrices de rango $r k x r ; \alpha$ representa la velocidad de ajuste hacia el equilibrio y $\beta$ un vector con las $r$ relaciones de cointegración (STATA, 2013).
} 
entre las variables del sistema $\left(B C_{t} ; Y^{d} ; Y^{f} ; e_{t}\right)$, empleamos la prueba multivariada de cointegración de Johansen (1995). De acuerdo con los criterios de traza y máximo valor se encontró que existe al menos un vector de cointegración. Con base en este resultado, se especificó un modelo VEC con una ecuación de cointegración, sin tendencia determinística en la relación de largo plazo y 4 rezagos en el vector de corrección (ver anexo).

Adicionalmente, se realizaron estimaciones de la ecuación (7) con base en una especificación Autorregresiva con Rezagos Distribuidos (ARDL) y mediante Mínimos Cuadrados Generalizados Factibles (MCGF), con el propósito de probar la consistencia de las estimaciones de largo plazo, dirección de asociación, mediante métodos alternativos. Según nuestros resultados, en largo plazo, el tipo de cambio real mantiene una relación positiva y estadísticamente significativa con la evolución de la balanza comercial. Por lo que una variación del $1 \%$ en tipo de cambio real (depreciación de la moneda nacional en 1\%) provoca una mejora de $1.1 \%$ en la balanza comercial.

Por otro lado, la evidencia sugiere una asociación negativa entre la demanda interna, capturada a través del Producto Interno Bruto de México, y la dinámica de la balanza comercial, en contraste la relación con la demanda externa, aproximada por el Producto Interno Bruto de Estados Unidos, es positiva. En este sentido, un aumento del $1 \%$ en el PIB de México y del PIB de Estados Unidos, generan un deterioro del $0.6 \%$ y un mejora del $0.7 \%$, respectivamente, sobre la balanza comercial.

Cuadro 3 Condición Marshall-Lerner Ecuación de largo plazo y velocidad de ajuste

\begin{tabular}{|c|c|c|c|}
\hline Variable & $\mathrm{VEC}^{/ 1}$ & $\mathrm{ARDL}^{/ 2}$ & $\mathrm{MCGF}^{/ 3}$ \\
\hline Constante & -0.9769 & -0.4729 & 0.6849 \\
\hline \multirow{2}{*}{$\ln Y^{d}$} & -0.6069 & -0.6085 & -0.6009 \\
& {$[0.071]^{\star \star}$} & {$[0.083]^{\star \star}$} & {$[0.047]^{\star}$} \\
\hline \multirow{2}{*}{$\ln Y^{f}$} & 0.7029 & 0.6663 & 0.5533 \\
& {$[0.030]^{\star}$} & {$[0.054]^{\star \star}$} & {$[0.071]^{\star \star}$} \\
\hline $\ln e$ & 1.1000 & 1.0319 & 0.8880 \\
& {$[0.000]^{\star}$} & {$[0.000]^{\star}$} & {$[0.000]^{\star \star}$} \\
\hline$\alpha$ & -0.3519 & -0.4248 & - \\
\hline
\end{tabular}

Fuente: Elaboración propia con base en información de la OCDE.

1/ Modelo de Vectores Autorregresivos con Corrección de Error (VEC)

2/ Modelos Autorregresivo con Rezagos Distribuidos (ARDL)

3/ Mínimos Cuadrados Generalizados Factibles (MCGF)

*Significativo al 5\%**Significativo al 10\% Valor-p entre paréntesis

Las estimaciones verifican, para el caso de la economía mexicana, que los volúmenes de exportaciones e importaciones son suficientemente elásticos con respecto al tipo de cambio real, esto es, que la suma del valor absoluto de las elasticidades precio de la demanda por exportaciones e importaciones es mayor que uno. Lo cual valida que en el largo plazo una depreciación del tipo de cambio real mejora la posición de la balanza comercial. 
94 Nueva Época REMEF (The Mexican Journal of Economics and Finance)

Asimismo, nuestros resultados confirman el sentido de las relaciones planteadas en el enfoque teórico convencional del comercio internacional acerca de las elasticidades ingreso doméstico y foráneo; el cual establece que la diferencia entre estas es un determinante de las variaciones de la balanza comercial, de tal manera que si $\beta_{1}<\beta_{2}$ entonces las importaciones no exceden las exportaciones mejorando el saldo de la balanza comercial, como verifican nuestras estimaciones (ver cuadro 4). Sin embargo, la brecha entre ambas elasticidades es reducida, lo cual podría presentar en el largo plazo una restricción sobre la senda de crecimiento de largo plazo. Toda vez que la economía mexicana denota dos patrones, un modelo importador-exportador y una mayor exportación de productos ensamblados.

Debemos destacar que los resultados encontrados en la especificación VEC, ecuación de largo plazo, son paralelos con los obtenidos bajo la metodología ARDL. La característica subyacente en ambos métodos es la especificación dinámica de la ecuación de estudio. En contraste, los resultados basados en el método de Mínimos Cuadrados Generalizados Factibles (MCGF), si bien denotan el signo esperado del modelo, la magnitud del coeficiente asociado al tipo de cambio real es menor que uno; una explicación plausible de este resultado es que MCGF no incorpora la interrelación de corto plazo y las características estocásticas estacionarias de los modelos dinámicos sobre las variables incluidas en el sistema.

Como hemos discutido, una consideración en el esquema de la regla Marshall-Lerner es que en el corto plazo una depreciación del tipo de cambio real empeora la posición de la balanza comercial, debido a que el efecto valor tiende a dominar sobre el efecto volumen, revirtiéndose esta dinámica en el largo plazo. Según la función de impulso-respuesta, ver gráfica 3, la balanza comercial evidencia un deterioro de corto plazo ante un choque en el tipo de cambio real, identificándose la curva J para la economía mexicana. 
Función de Impulso - Respuesta entre Balanza Comercial y Tipo de Cambio

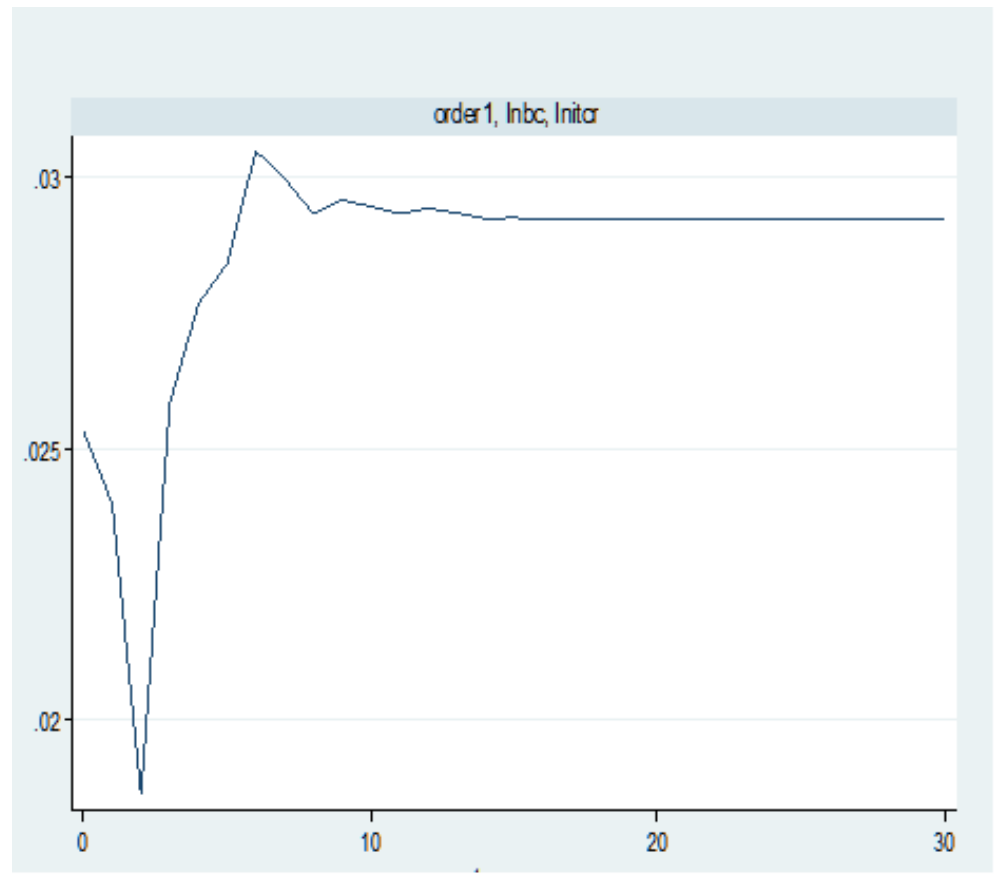

Desde nuestra perspectiva, el planteamiento de la condición Marshall-Lerner apunta a la mejora de la competitividad de una economía, pequeña y abierta, a partir de los movimiento del tipo de cambio real; sin que esto signifique una ganancia en términos de productividad e innovación tecnológica. Esto significa, que una economía en un contexto de especialización en industrias tradicionales o con bajo aporte de valor agregado, la competitividad e inserción al mercado mundial solo se sustentarían en las variaciones del tipo de cambio real.

\section{Conclusiones}

En este artículo se ha cuantificado el efecto de las variaciones del tipo de cambio real sobre la balanza comercial para el caso de la economía mexicana, siguiendo la regla Marshall-Lerner durante el periodo 1986-2014. En la primera parte del análisis, se ha mostrado que el comercio exterior de México ha aumentado vigorosamente durante el periodo de referencia; caracterizado, por una parte, por un dinamismo exportador basado en un alto contenido de insumos importados, correspondiente a las nuevas formas de producción a escala global; por otra, por la alta concentración de sus exportaciones al mercado norteamericano y una gradual diversificación de las importaciones, siendo Asia la región con mayor dinamismo. De esta misma sección, se desprende la notable sensibilidad de la competitividad del sector exportador a las fluctuaciones del tipo de cambio. Durante la fase de tipos de cambio fijo, la brecha en el diferencial de precios entre Estados Unidos y México representó el principal elemento de desajuste en la pérdida de competitividad; mientras que durante la 
fase de tipo de cambio flexible el principal desajuste se cimenta en la variabilidad del tipo de cambio nominal, el cual es determinado por los flujos de entrada y salida de divisas al país.

En la segunda parte, derivado de nuestras estimaciones empíricas, encontramos que en el largo plazo la variabilidad del tipo de cambio real mejora la posición de la balanza comercial; en contraste, en el corto plazo, nuestros resultados sugieren que un aumento del índice del tipo de cambio real empeora la balanza comercial, verificando la presencia de la curva J.

$\mathrm{Si}$ bien, las estimaciones empíricas verifican el esquema teórico, es importante observar: el diferencial entre la elasticidad ingreso por exportaciones e importaciones, así como la magnitud del coeficiente de la elasticidad precio. Debido a que un efecto de cancelación en las primeras y la presencia de un valor cercano a uno en el segundo, podrían ejercer posibles restricciones al crecimiento económico en el largo plazo. Para futuras investigaciones queda por analizar esta dinámica con la restricción del crecimiento por balanza de pagos.

\section{Bibliografía}

Acevedo, E. y J. Zabludovsky (2012). Evaluación de la Apertura Comercial Internacional, en Reflexiones sobre la política comercial internacional de México 2006-2012 (2012). Coordinadora Beatriz Leycegui Gardoqui Et al, Editorial miguel ángel Porrúa, México.

Bustamante, R. y F. Morales (2009). Probando la condición de Marshall-Lerner y el efecto Curva-J: Evidencia empírica para el caso peruano. Estudios Económicos 16, Banco Central de Reserva del Perú.

De La Cruz, J., Koopman, R. B. y Wang, Z. (2011). Estimating Foreign Value-added in Mexico's Manufacturing Exports. Office of Economics Working Paper U.S. International Trade Commission. No. 2011-04A.

Estrada, J. L. y R. Arriaga (2004). La productividad en las manufacturas mexicanas durante la liberalización comercial y los acuerdos comerciales. El Nuevo Milenio Mexicano, Tomo 3: El Cambio Estructural, Ed. UAMA y EÓN.

Galindo, L. M., y C. Guerrero (1997). Factores determinantes de la balanza comercial de México, 1980-1995. Revista de Comercio Exterior, 47(10), México. pp. 789-794.

Gómez, M. y A. Rodríguez (2011). El Tipo de Cambio Real y los Regímenes Cambiarios en México Durante el Periodo 1954-2010. CIMEXUS, 6(1). Universidad Michoacana de San Nicolás de Hidalgo, Instituto de Investigaciones Económicas y Empresariales.

Hernández, B. P., Rivero, T. A. y P. I. Frías (2012). El tipo de cambio real, el ingreso nacional y el ingreso foráneo en la determinación de la balanza comercial en Bolivia: 1992-2011, Revista Nicolaita de Estudios Económicos, VII(2), pp.27-46.

Kalyoncu, H., I. Ozturk, S. Artan, y K. Kalyoncu (2009). Devaluation an Trade Balance in Latin American Countries. Journal of Economics and Business, Faculty of Economics Rijeka, 27, pp. 115-128.

Klaus S. (2012). Las políticas de comercio e inversión, incentivo para la competitividad de México. En Reflexiones sobre la política comercial internacional de México 2006-2012. Coordinadora Beatriz Leycegui Gardoqui Et al, Editorial miguel ángel Porrúa, México.

Krugman, P.(1995). Growing Worl Trade: Causes and Consequences. Brookings Papers on Economic Activity, 1, pp. 327-377.

Landa, H. (2010). Crecimiento económico y apertura económica en México: el rol de las externalidades y las capacidades tecnológicas. Tesis Doctoral. Universidad Autónoma Metropolitana.

Leycegui, G. B. (2012). Reflexiones sobre la política comercial internacional de méxico 20062012. Libro Colectivo, Editorial Miguel Ángel Porrúa, México.

Macías, A. (2003). Tipo de cambio y paridad del poder de compra en México. Revista de Comercio Exterior, 53(9), Septiembre de 2003. 
Pacheco, L., P. (2005). Liberalización de la política comercial y crecimiento económico de México. Economía-UNAM, Vol.2(4).

Rendón, H. y R. A. Hassan (2005). Condición Marshall-Lerner: una aproximación al caso colombiano, 1980-2001. Ecos de Economía No. 20. pp. 29 - 58.

Romero, J. (2009). Medición del Impacto de Los Acuerdos de Libre Comercio En América Latina: El Caso de México. Serie Estudios y Perspectivas 114, CEPAL, México.

Sastre, J. L. (2010). Economías abiertas y condición de Marshall-Lerner. Economic Analysis Working Papers. Atlantic Review of Economics, 9(9). pp. 1-8

Sánchez, M. (2012). Economía mexicana: Una mirada de largo plazo, presentación de Banxico en UC Alumni Club, Buenos Aires.

\section{ANEXO}

Orden de Integración Prueba de Raíz Unitaria

\begin{tabular}{|c|c|c|c|c|c|c|c|c|}
\hline \multirow{2}{*}{ País } & \multicolumn{3}{|c|}{ Dickey-Fuller Augmented } & \multicolumn{3}{|c|}{ Phillips-Perron } & \multirow{2}{*}{$\begin{array}{c}\# \\
\text { Rezago }\end{array}$} & \multirow{2}{*}{$\mathrm{I}(\mathrm{d})$} \\
\hline & I & I y T & Sin I y T * & I & I y T & Sin I y $T^{*}$ & & \\
\hline $\ln b c$ & $\begin{array}{c}-2.886 \\
{[0.0470]}\end{array}$ & $\begin{array}{c}-2.785 \\
{[0.2027]}\end{array}$ & -0.733 & $\begin{array}{c}-2.498 \\
{[0.1160]}\end{array}$ & $\begin{array}{c}-2.501 \\
{[0.3272]}\end{array}$ & -0.617 & 2 & $l(1)$ \\
\hline $\ln Y^{d}$ & $\begin{array}{c}-1.001 \\
{[0.7530]}\end{array}$ & $\begin{array}{c}-3.210 \\
{[0.0824]}\end{array}$ & 3.696 & $\begin{array}{c}-0.530 \\
{[0.8861]}\end{array}$ & $\begin{array}{c}-2.738 \\
{[0.2208]}\end{array}$ & 4.392 & 2 & $l(1)$ \\
\hline $\ln Y^{f}$ & $\begin{array}{c}-1.697 \\
{[0.4327]}\end{array}$ & $\begin{array}{c}-1.095 \\
{[0.9298]}\end{array}$ & 3.261 & $\begin{array}{c}-2.028 \\
{[0.2743]}\end{array}$ & $\begin{array}{c}-0.620 \\
{[0.9779]}\end{array}$ & 7.492 & 3 & $l(1)$ \\
\hline lne & $\begin{array}{c}-2.813 \\
{[0.0564]}\end{array}$ & $\begin{array}{c}-2.864 \\
{[0.1744]}\end{array}$ & -0.743 & $\begin{array}{c}-2.682 \\
{[0.0772]}\end{array}$ & $\begin{array}{c}-2.848 \\
{[0.1798]}\end{array}$ & -0.707 & 4 & $l(1)$ \\
\hline$\Delta \operatorname{lnbc}$ & $\begin{array}{c}-6.509 \\
{[0.0000]}\end{array}$ & $\begin{array}{c}-6.687 \\
{[0.0000]}\end{array}$ & -6.452 & $\begin{array}{c}-8.713 \\
{[0.0000]}\end{array}$ & $\begin{array}{c}-8.693 \\
{[0.0000]}\end{array}$ & -8.740 & 2 & $l(0)$ \\
\hline$\Delta \ln Y^{d}$ & $\begin{array}{c}-6.730 \\
{[0.0000]}\end{array}$ & $\begin{array}{c}-6.728 \\
{[0.0000]}\end{array}$ & -5.273 & $\begin{array}{c}-7.203 \\
{[0.0000]}\end{array}$ & $\begin{array}{c}-7.176 \\
{[0.0000]}\end{array}$ & -6.057 & 1 & $l(0)$ \\
\hline$\Delta \ln Y^{f}$ & $\begin{array}{c}-4.261 \\
{[0.0005]}\end{array}$ & $\begin{array}{c}-4.548 \\
{[0.0013]}\end{array}$ & -2.433 & $\begin{array}{c}-7.038 \\
{[0.0000]}\end{array}$ & $\begin{array}{c}-7.367 \\
{[0.0000]}\end{array}$ & -3.951 & 2 & $l(0)$ \\
\hline$\Delta \ln e$ & $\begin{array}{l}-11.002 \\
{[0.0000]}\end{array}$ & $\begin{array}{l}-11.005 \\
{[0.0000]}\end{array}$ & -11.011 & $\begin{array}{l}-11.030 \\
{[0.0000]}\end{array}$ & $\begin{array}{l}-11.042 \\
{[0.0000]}\end{array}$ & -11.034 & 3 & $l(0)$ \\
\hline
\end{tabular}

El cuadro reporta el valor del estadístico $Z(t)$, así como el valor- $p$ correspondiente (entre corchetes). I: Intercepto, I y T: intercepto y tendencia.

Orden de Integración Prueba de Raíz Unitaria

\begin{tabular}{|c|c|c|c|c|c|c|}
\hline \multicolumn{2}{|c|}{ Trend: constant } & Johan & \multirow[t]{2}{*}{ n tests for } & cointegration & \multirow{2}{*}{ Number of obs $=$} & \multirow{2}{*}{$\begin{array}{r}113 \\
1\end{array}$} \\
\hline Sample: & $1986 q^{2}$ & $2014 q 2$ & & & & \\
\hline & & & & & 58 & \\
\hline maximum & & & & trace & critical & \\
\hline rank & parms & LI & eigenvalue & statistic & value & \\
\hline 0 & 4 & 1091.2605 & . & 65.3425 & 47.21 & \\
\hline 1 & 11 & 1113.193 & 0.32171 & $21.4776 \star$ & 29.68 & \\
\hline 2 & 16 & 1118.8442 & 0.09518 & 10.1752 & 15.41 & \\
\hline 3 & 19 & 1121.7656 & 0.05039 & 4.3322 & 3.76 & \\
\hline \multirow[t]{2}{*}{4} & 20 & 1123.9318 & 0.03761 & & & \\
\hline & & & & & 58 & \\
\hline maximum & & & & $\max$ & critical & \\
\hline rank & parms & LI & eigenvalue & statistic & value & \\
\hline 0 & 4 & 1091.2605 & . & 43.8650 & 27.07 & \\
\hline 1 & 11 & 1113.193 & 0.32171 & 11.3024 & 20.97 & \\
\hline 2 & 16 & 1118.8442 & 0.09518 & 5.8429 & 14.07 & \\
\hline 3 & 19 & 1121.7656 & 0.05039 & 4.3322 & 3.76 & \\
\hline 4 & 20 & 1123.9318 & 0.03761 & & & \\
\hline
\end{tabular}


Orden de Integración Prueba de Raíz Unitaria

\begin{tabular}{|c|c|c|c|c|c|c|}
\hline \multicolumn{4}{|c|}{ 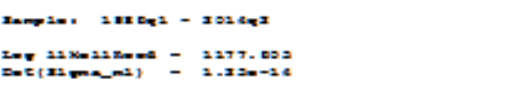 } & \multicolumn{2}{|c|}{ 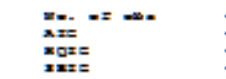 } & \multirow[t]{3}{*}{ 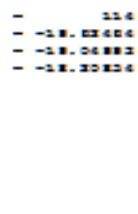 } \\
\hline$x_{4}=\mathrm{Cs}_{2}$ & & $\operatorname{xxax}$ & $x=$ & $\sin x$ & $n=1 x$ & \\
\hline 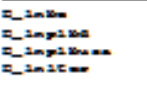 & $\begin{array}{l}\text { is } \\
\text { is } \\
\text { is }\end{array}$ & 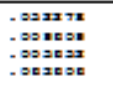 & $\begin{array}{l}0.027 x \\
0.2022 \\
0.0622 \\
0.2627\end{array}$ & 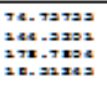 & $\begin{array}{l}0.0000 \\
0.0000 \\
0.0000 \\
0.3112\end{array}$ & \\
\hline & $=m=$ & xwa. xay- & - & $=101$ & 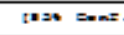 & 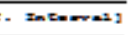 \\
\hline \multicolumn{7}{|l|}{$=-1 m-$} \\
\hline$x=$ & - & $.00 x 200$ & -3.37 & 0.000 & - - & $-\operatorname{sxn}=$ \\
\hline 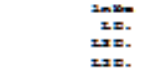 & 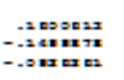 & 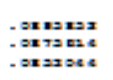 & $\begin{array}{l}=.-7.8 \\
-2.71 \\
-2.08\end{array}$ & $\begin{array}{l}0.076 \\
0.0 x 7 \\
0 . x 7 x\end{array}$ & 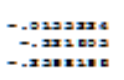 & 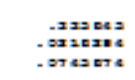 \\
\hline 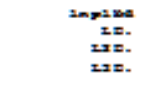 & 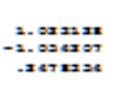 & 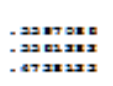 & $\begin{aligned} 2 . x x \\
-1.20 \\
0.2 x\end{aligned}$ & $\begin{array}{l}0.00 x \\
0.03 x \\
0.032\end{array}$ & 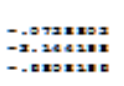 & 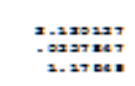 \\
\hline 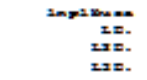 & 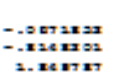 & 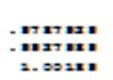 & $\begin{aligned}-5.07 \\
-0.2 x \\
2 . x=\end{aligned}$ & $\begin{array}{l}0.2 x \\
0.02 x \\
0.0 x\end{array}$ & 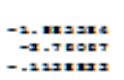 & 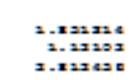 \\
\hline 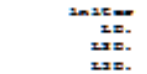 & 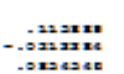 & 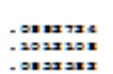 & $\begin{aligned} 2.27 \\
-6.21 \\
0.10\end{aligned}$ & $\begin{array}{l}0 . x e x \\
0 . \sin \\
0 . x 70\end{array}$ & 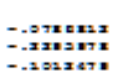 & 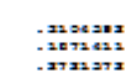 \\
\hline$\ldots$ & -.0008628 & . о5:Eets & $-5.4 x$ & 0. etx & $-.03002=$ & . $02 \sin x+x$ \\
\hline \multicolumn{7}{|l|}{ Insminas } \\
\hline x=. & $-.02 x \times 287$ & 7 & $-x .7 x$ & 0.000 & -.0201020 & -.000406 \\
\hline 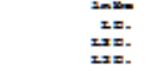 & 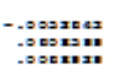 & 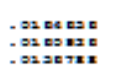 & $\begin{aligned}-0.3 x \\
x=7 x \\
0 .-64\end{aligned}$ & $\begin{array}{l}0.708 \\
0.008 \\
0 .-608\end{array}$ & 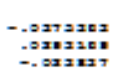 & 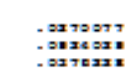 \\
\hline $\sin x i v a$ & & & & & & \\
\hline $\begin{array}{l}x=- \\
x=1 \\
x=0\end{array}$ & 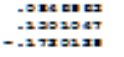 & 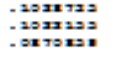 & $\begin{aligned} 0 . x x \\
2.27 \\
-2.2 x\end{aligned}$ & $\begin{array}{l}0.210 \\
0.26 x \\
0.06 x\end{array}$ & 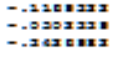 & 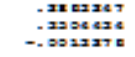 \\
\hline 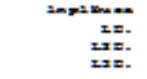 & 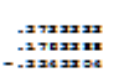 & 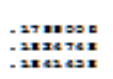 & $\begin{array}{r}x .87 \\
0.87 \\
-2 . x x\end{array}$ & 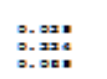 & 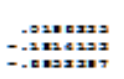 & 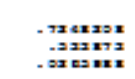 \\
\hline 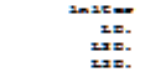 & 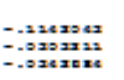 & 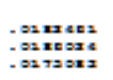 & $\begin{array}{l}-E . x E \\
-2.2 x \\
-2 . x\end{array}$ & $\begin{array}{l}0.000 \\
0.102 \\
0.000\end{array}$ & 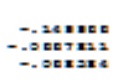 & 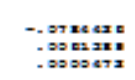 \\
\hline$-\cdots$ & $. \cos 2 x=$ & .0023216 & $x . x x$ & 0.002 & .0032087 & $.000207 x$ \\
\hline
\end{tabular}


Orden de Integración Prueba de Raíz Unitaria

\begin{tabular}{|c|c|c|c|c|c|c|}
\hline \multicolumn{7}{|l|}{$=2 \sin 2 \ln 2}$. \\
\hline$x=$ & $-.0002 x 18$ & $-00 \mathrm{cts} x$ & $=0.72$ & $0.42 x$ & $-.02 \times 2287$ & $.005 x 42$ \\
\hline 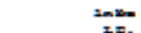 & $-0.0900 x$ & & & & & 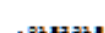 \\
\hline $\begin{array}{l}x=0 . \\
x=0 .\end{array}$ & 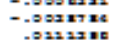 & 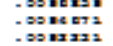 & $\begin{array}{r}-2.07 \\
-9.42 \\
2.12\end{array}$ & $\begin{array}{l}0.2 x \\
0 . \operatorname{cax} \\
0 .-1 x y\end{array}$ & 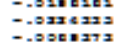 & 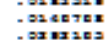 \\
\hline \multicolumn{7}{|l|}{ Impinat } \\
\hline$x=$ & -.00722012 & - 00002024 & $-0.2 x$ & 0.024 & -.1201872 & $-22212 \mathrm{kn}$ \\
\hline$x=0$ & $--0.87 \pi x$ & $-0002 \pi x=$ & $-2.7 x$ & 0.027 & -12060232 & -9720028 \\
\hline & -004027 & - $0202 x+15 x$ & $0.0 x$ & $0.0 x 7$ & $-.082 x=5$ & $-20464 x 7$ \\
\hline \multicolumn{7}{|l|}{ ampiand... } \\
\hline$x=$ & -xexase & $-2021 x=2$ & $x-87$ & $0.00 x$ & -отаоека & $-4 x=008$ \\
\hline $2 x=$ & -2120202 & $-207245 X$ & 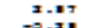 & 0.002 & -105xxy & - $2 x=10 x$ \\
\hline $2 x=$ & $-.022000 x$ & $-20 \cos x$ & $\rightarrow-x=$ & $0.70 x$ & $-. x 42 x=22$ & $.2 \times 582$ \\
\hline \multicolumn{7}{|l|}{$=\sin 2 x-\infty$} \\
\hline$x=$ & $-.02 x \times 2=20$ & - $02072 x 1$ & $-2 . x x$ & $0 . \ln x$ & $-.024 \times 4 \times x$ & | \\
\hline$x=$ & .0020067 & $-02014 x x$ & 0.24 & $0.7 x=$ & 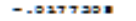 & $-0 x 22042$ \\
\hline $2 x=$ & נבצבד -000. & $-0200 \mathrm{sex}$ & -0.72 & 0.872 & - -.027 ד & 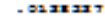 \\
\hline$-m$ & $-00217 x$ & -000020 & $=.40$ & 0.002 & -0022427 & T-0020207 \\
\hline \multicolumn{7}{|l|}{$=$ _amac- } \\
\hline \multirow{2}{*}{\multicolumn{7}{|c|}{$-07 \cos x$}} \\
\hline & & & & & & \\
\hline$x=$ & $-.2 x 72306$ & - $20 \mathrm{xanx}$ & -2.27 & $0 . x e x$ &.$- x 40000 x$ & - $0 x+202$ \\
\hline$x=$ & $-.2 x x 062 x$ & $.2002 x e 0$ & -2.22 & $0 . x e x$ &.$- x x 2 x 42 x$ & . $91270 x$ \\
\hline $2 x=$ & $-.2 x 2078$ & $.2027112=$ & $-2.2=$ & $0 . x x$ & $-. x \times 190$ & - 07neses \\
\hline \multicolumn{7}{|l|}{ sominas } \\
\hline$x=$ & $=2.205262$ & Exontet & $2 .-1 x$ & 0.022 & - -0xEstre & x-esceses \\
\hline $2 x=$ & - -.20xack & - $67002 x$ & $-5 . x 7$ & $0.7 \pi 4$ & -1.22242 & 2.24001 \\
\hline $2 x=$ & -.02812023 & $-2706 x$ & -0.00 & 0.200 & -2.2000020 & $2.000 x+2$ \\
\hline \multicolumn{7}{|l|}{ amplatenc... } \\
\hline Ix- & -2. 117400 & $2-2 \cos x x$ & -1.28 & $0 . x 2=$ & $-x \cdot 720 \cos x$ & 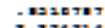 \\
\hline$x=$ & 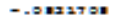 & $2 . x \cos x$ & $-\infty .0 x$ & $0.2 x=$ & $-x-4 \cos 0$ & $x-x>2 x 4$ \\
\hline $2 x=$ & -402820 & $2 . x 2 x=4$ & $0 . x x$ & $0.74 x$ & -2. & $x-700=2$ \\
\hline \multicolumn{7}{|l|}{$2 \operatorname{sic} 2$} \\
\hline$x=$ & $.20 x 2020$ & $-2 x 070212$ & $=.20$ & 0.284 & $-.0050 x=2$ & $-4 \sec 2 x$ \\
\hline \multirow{2}{*}{$\begin{array}{l}x=0 . \\
x=0 .\end{array}$} & -onescas & $-232242=$ & 0.74 & $0.42 x$ & $-.24812 x=2$ & אובד \\
\hline & $-x 210784$ & $.22=2102$ & $x=1 x$ & 0.002 & $-122 x 28 x$ & - 200202x \\
\hline$-\cdots$ & -.007 Eater & $-0202025=$ & $=0.7 x$ & 0.485 & $-.03 \times 1210$ & $.02 x+20 x$ \\
\hline \multicolumn{7}{|c|}{ 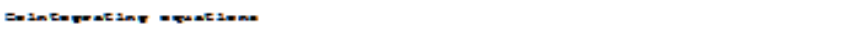 } \\
\hline \multicolumn{7}{|l|}{ xquese- } \\
\hline \multicolumn{7}{|c|}{$x=0.200$} \\
\hline \multicolumn{7}{|c|}{ 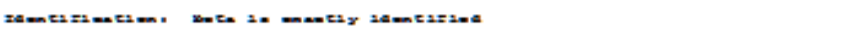 } \\
\hline \multicolumn{7}{|c|}{ 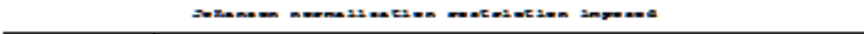 } \\
\hline 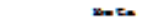 & $=-=$ & xca. - xa- & - & $=1=1$ & $t+20=m=-$ & 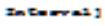 \\
\hline \multirow{2}{*}{\multicolumn{7}{|c|}{$-\infty$}} \\
\hline & & & & & & \\
\hline $2 \log 20$ & $-\cos n$ & $-\operatorname{sx} \operatorname{cosin} x$ & $2=0$ & 0.072 & $-.02 x=202$ & $2 . x \operatorname{cosec}$ \\
\hline ampinan. & $-.70 x \mathrm{kng}$ & $-2 x \geq 2 x$ & $-x-27$ & 0.020 & $-2.2 x=7 x 2$ & $-.0 \mathrm{cosen}$ \\
\hline 2ase- & $-2.00202 x$ & $-0200 \times 24$ & $-2 x .87$ & 0.020 & -2.277487 & $-.0000 \mathrm{ex}=$ \\
\hline$-\infty$ & $-\operatorname{cosex}$ & & & & & \\
\hline
\end{tabular}


100 Nueva Época REMEF (The Mexican Journal of Economics and Finance)

Orden de Integración Prueba de Raíz Unitaria

\begin{tabular}{|r|rrc|}
\hline lag & chi2 & df & Prob > chi2 \\
\hline 1 & 24.6288 & 16 & 0.07664 \\
2 & 22.2263 & 16 & 0.13603 \\
3 & 14.7866 & 16 & 0.54032 \\
4 & 9.5446 & 16 & 0.88931 \\
5 & 13.9214 & 16 & 0.60457 \\
\hline
\end{tabular}

Orden de Integración Prueba de Raíz Unitaria

\begin{tabular}{|c|c|c|}
\hline \multicolumn{2}{|c|}{ Eigenvalue } & \multirow{2}{*}{$\begin{array}{r}\text { Modulus } \\
1\end{array}$} \\
\hline 1 & & \\
\hline 1 & & 1 \\
\hline 1 & & 1 \\
\hline .4208932 & $.530134 i$ & .6769 \\
\hline .4208932 & $.530134 i$ & .6769 \\
\hline .6742561 & & .674256 \\
\hline-.3336371 & $+.5825365 i$ & .671314 \\
\hline-.3336371 & - $.5825365 i$ & .671314 \\
\hline .633237 & $+.2102022 i$ & .667214 \\
\hline .633237 & $-\quad .2102022 i$ & .667214 \\
\hline-.6045826 & & .604583 \\
\hline .2626222 & $+.4640098 i$ & .533175 \\
\hline .2626222 & $-.4640098 i$ & .533175 \\
\hline-.2925703 & $+.3058148 i$ & .423226 \\
\hline-.2925703 & $-\quad .3058148 i$ & .423226 \\
\hline-.2807666 & & .280767 \\
\hline
\end{tabular}


Orden de Integración Prueba de Raíz Unitaria

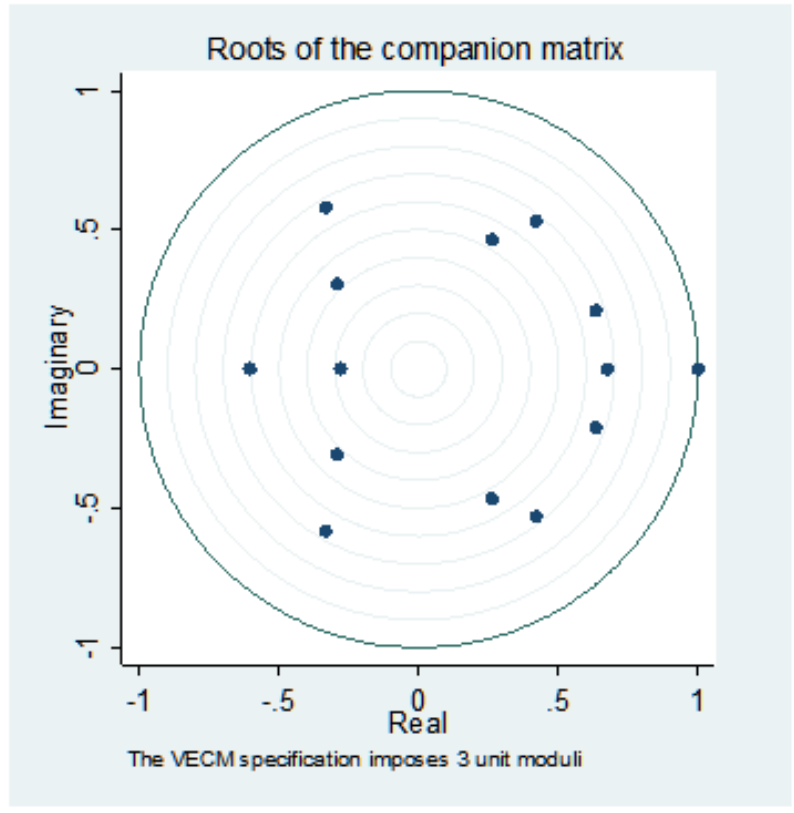

Orden de Integración Prueba de Raíz Unitaria

\begin{tabular}{|c|c|c|c|c|c|c|c|c|c|c|c|c|c|}
\hline \multirow{2}{*}{\multicolumn{7}{|c|}{ 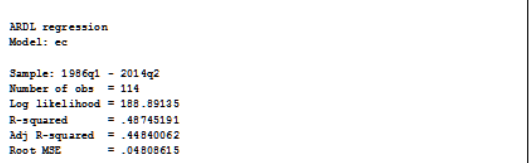 }} & \multicolumn{4}{|c|}{ 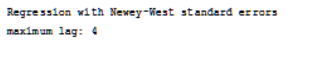 } & \multicolumn{3}{|c|}{ 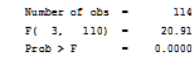 } \\
\hline & & & & & & & $1 \mathrm{nbc}$ & & $\begin{array}{l}\text { Wever-hest } \\
\text { Sta. Zart. }\end{array}$ & $\mathrm{t}$ & $\mathrm{B}|\mathrm{t}|$ & [954 Conf. & Interval] \\
\hline D. 1 nbe & Coef. & $\mathrm{stad}_{\mathrm{s} r \mathrm{r}}$ & $t$ & $B>|t|$ & [958 Conf. & Inter vall] & 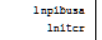 & $\begin{array}{l}.5539076 \\
.8380362\end{array}$ & $\begin{array}{l}.30331599 \\
.12989736\end{array}$ & $\begin{array}{l}1.1 .12 \\
5.95\end{array}$ & $\begin{array}{l}0.071 \\
0.0000\end{array}$ & 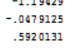 & 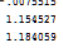 \\
\hline & & & & & & & & & & & & & \\
\hline t1. & -4248533 & .051993 & -8.17 & 0.000 & -.52794577 & -..22176009 & & & & & & & \\
\hline 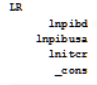 & 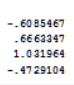 & 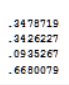 & 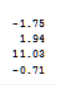 & 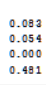 & 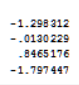 & 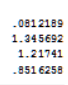 & & & & & & & \\
\hline 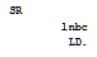 & .1462991 & .0748228 & 1.96 & 0.053 & -0.0220007 & .294588 & & & & & & & \\
\hline $\begin{array}{c}\text { Inpipd } \\
\text { D1. } \\
\text { tD. } \\
\text { tD. }\end{array}$ & $\begin{array}{r}-6787985 \\
-7242799\end{array}$ & .4.4228975 4.41410898 & $\begin{array}{c}-1.60 \\
1.175\end{array}$ & $\begin{array}{l}0.112 \\
0.093\end{array}$ & $\begin{array}{l}-1.5177266 \\
-.09868219\end{array}$ & $\begin{array}{l}1.159979292 \\
1.5455891\end{array}$ & & & & & & & \\
\hline 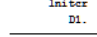 &.- .1677272 & .0891755. & -1.84 & 0.069 &.- .3405457 & . 0120912. & & & & & & & \\
\hline
\end{tabular}

